\title{
Crescimento e teor de proteínas em sementes de soja sob influência de hormônios vegetais
}

\author{
RONALDO DO NASCIMENTO ${ }^{1,3}$ e PAULO R. MOSQUIM ${ }^{2}$
}

(recebido: 30 de outubro de 2002; aceito: 20 de maio de 2004)

\begin{abstract}
Growth and protein content in soybean seeds affected by phytohormones). The phytohormones likely to be envolved in growth and protein reserve accumulation in soybean seeds were studied by artificial cultivation of fruits. Explants from soybean fruits with pericarp fully expanded and seeds with $100 \mathrm{mg}$ of fresh mass were cultivated in vitro with naphthalene acetic acid (NAA), gibberelic acid ( $\mathrm{GA}_{3}$ ), benzylad enine (BA) and abscisic acid (ABA) initially alone at $10^{-7}, 10^{-6}, 10^{-5}$ and $10^{-4}$ mol.L-1 rates. Phytoregulators combinations were determined as a function of greater increments in seeds dry weight. On the basis of previous observations of. $\mathrm{GA}_{3}$ and $\mathrm{BA}$ promoted seed development only in high concentrations, while NAA was ineffective and ABA inhibited seed growth. When applied concurrently with $\mathrm{GA}_{3}$ or BA, the NAA stimulated seed growth, suggesting that interactions may occur among them. NAA and BA alone or combined induced increase in seed protein content but ABA inhibited the protein accumulation. The artificial cultivation system employed in this assay has been shown to be suitable for studies of growth and protein accumulation in soybean seeds.
\end{abstract}

Key words - explants, gibberelic acid, phytoregulators

RESUMO - (Crescimento e teor de proteínas em sementes de soja sob influência de hormônios vegetais). Os prováveis hormônios vegetais envolvidos no crescimento e acúmulo de proteínas de reserva em sementes de soja foram avaliados por meio do cultivo artificial dos frutos. Explantes de frutos de soja apresentando o pericarpo completamente expandido e sementes com aproximadamente $100 \mathrm{mg}$ de massa fresca foram cultivados in vitro com várias concentrações de ácido naftaleno-acético (ANA), ácido giberélico $\left(\mathrm{GA}_{3}\right)$, benziladenina (BA) e ácido abscísico (ABA). Esses fitorreguladores foram utilizados inicialmente isolados nas concentrações de $10^{-7}, 10^{-6}, 10^{-5}$ e $10^{-4}$ mol.L $\mathrm{L}^{-1}$ cada um. Em seguida, foram combinados dois a dois, sendo as concentrações determinadas em função dos maiores incrementos na massa seca das sementes observados nos experimentos iniciais. O ANA foi ineficiente para o crescimento das sementes, que foi estimulado por GA $\mathrm{GA}_{3}$ BA, porém apenas nas

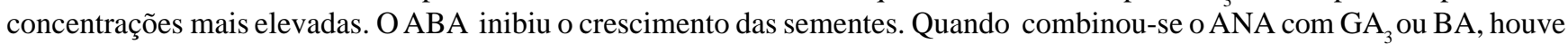
aumento na massa seca das sementes, sugerindo que pode ocorrer interações entre hormônios vegetais. O ANA e a BA foram os fitorreguladores mais eficientes no acúmulo de proteínas, tanto isolados como combinados. O ABA, por sua vez, inibiu a síntese de proteínas de reserva nas sementes. O sistema artificial de cultivo utilizado nesse experimento mostrou-se eficiente para o estudo do crescimento e de teores protéicos em sementes de soja.

Palavras-chave - ácido giberélico, explantes, fitoreguladores

\section{Introdução}

Dentre as várias leguminosas tropicais e subtropicais cultivadas no Brasil, a soja destaca-se como uma das principais, econômica e nutricionalmente, em função do alto teor protéico das sementes (Schrader \& Thomas 1981), que para se desenvolverem dependem de um suprimento de minerais e hormônios vegetais fornecidos pela planta. No entanto, complexas interações que ocorrem entre as sementes em formação e a plantamãe tornam difícil a identificação de quais hormônios

1. Universidade Federal de Pelotas, Instituto de Biologia, Departamento de Botânica, Campus Universitário, 96910-900 Pelotas, RS, Brasil.

2. Universidade Federal de Viçosa, Centro de Ciências Biológicas e da Saúde, Departamento de Biologia Vegetal, Campus Universitário, 36571-000 Viçosa, MG, Brasil.

3. Autor para correspondência: ronascim@ufpel.tche.br vegetais estão envolvidos no crescimento das sementes e no acúmulo de proteínas. Segundo Obendorf et al. (1983), uma maneira de diminuir essa dificuldade é isolar os frutos em formação e cultivá-los em meio artificial adequado.

Das técnicas utilizadas para o cultivo artificial de frutos de soja, têm-se a do tegumento vazio, desenvolvida por Thorne (1981), a da cultura de cotilédones imaturos, desenvolvida por Thompson et al. (1977), e a do cultivo de explantes de frutos, desenvolvida por Mosquim \& Sodek (1991). Dentre elas, a que melhor reproduz as condições da planta é o cultivo de explantes de frutos, uma vez que os nutrientes alcançam as sementes via fluxo xilemático. A utilização dessa técnica foi útil para verificação de vários aspectos bioquímicos nas sementes de soja, como o transporte e metabolismo de substâncias nitrogenadas (Mosquim \& Sodek 1991), a distribuição de carboidratos e atividade 
de invertases (Nascimento et al. 1998) e a atividade das enzimas sintetase da glutamina e sintase do glutamato nos frutos sob diferentes fontes de nitrogênio (Junghans \& Mosquim 1995).

Entretanto, os efeitos de hormônios vegetais sobre o crescimento das sementes de soja são pouco conhecidos, embora já exista alguma informação com frutos de ervilha (Ozga et al. 1992, Van Huizen et al. 1996, Van Huizen et al. 1997). Observou-se que sementes imaturas de ervilha contêm quantidades elevadas de auxinas e giberelinas, as quais estão envolvidas com seu crescimento. Além de influenciar o crescimento das sementes, os hormônios vegetais podem induzir a síntese protéica, conforme verificado por Van Huizen et al. (1996). Esses autores observaram que a síntese de proteínas em sementes de ervilha foi detectada dentro de seis horas após a aplicação de auxinas e giberelinas.

O presente trabalho teve por objetivos verificar, por meio do cultivo in vitro de explantes de frutos de soja, o efeito de fitorreguladores no crescimento das sementes, bem como avaliar a influência dessas substâncias sobre o acúmulo de proteínas de reserva nos cotilédones.

\section{Material e métodos}

Sementes de soja [Glycine $\max ($ L.) Merril cv. UFV 16] foram semeadas em vasos de polietileno, com capacidade para $3 \mathrm{~L}$, contendo areia lavada como substrato e mantidas em casa de vegetação em condições naturais de luz, temperatura e umidade relativa de outubro de 1997 a dezembro de 1998.

Após germinação, quando as plântulas apresentaram o primeiro trifólio completamente expandido, foi feito um desbaste, deixando-se apenas duas plântulas por vaso. Estas foram irrigadas sempre que necessário com água e, três vezes por semana, foram aplicados $250 \mathrm{~mL}$ da solução nutritiva completa de Hoagland (Hoagland \& Arnon 1938). As plantas permaneceram naquelas condições até que os frutos apresentassem o pericarpo completamente expandido e as sementes com cerca de $100 \mathrm{mg}$ de massa fresca, quando foram transferidas ao laboratório para a montagem dos experimentos.

Para o cultivo de explantes de frutos de soja, utilizou-se a metodologia descrita por Mosquim \& Sodek (1991). A fonte de carboidratos foi a sacarose e a de nitrogênio, a glutamina, na concentração de $50 \mathrm{mg} \cdot \mathrm{mL}^{-1}$ e de $1,2 \mathrm{mg} \cdot \mathrm{mL}^{-1}$ de $\mathrm{N}$ no meio de cultivo, respectivamente.

Para avaliar a influência de cada fitorregulador sobre o crescimento das sementes, foi adicionado, separadamente ao meio de cultivo, ácido naftaleno-acético (ANA), ácido giberélico $\left(\mathrm{GA}_{3}\right)$, benziladenina (BA) e ácido abscísico (ABA), todos nas concentrações de $10^{-7}, 10^{-6}, 10^{-5}$ e $10^{-4}$ mol.L ${ }^{-1}$. Cada fitorregulador correspondeu a um experimento. Após conhecer a concentração de cada fitorregulador que proporcionou o maior incremento na massa seca das sementes, estas foram fixadas, variando-se, então, a concentração dos outros fitorreguladores, de $10^{-7}$ a $10^{-4}$ mol. $\mathrm{L}^{-1}$. O pH de todos os meios de cultivo foi ajustado para 5,0. Utilizaram-se $6,5 \mathrm{~mL}$ de cada meio de cultivo. A cada 48 horas, os caules dos explantes foram cortados em sua base em cerca de dois mm para desobstruir algum vaso que poderia estar bloqueado e, no quarto dia, os meios de cultivo foram trocados para evitar exaustão de minerais ou substâncias orgânicas. O período de cultivo para os quatro experimentos iniciais foi de 10 dias e, para os experimentos subseqüentes, foi de 8 dias. Frutos foram coletados e suas sementes analisadas nos dias da montagem (controle in situ, dia 0) e desmontagem (controles in situ, dia 8 ou 10) dos experimentos. $\mathrm{O}$ sistema de cultivo in vitro foi então colocado sob iluminação contínua de aproximadamente $80 \mu \mathrm{mol} . \mathrm{m}^{-2} . \mathrm{s}^{-1}$ e temperatura de $25 \pm 2{ }^{\circ} \mathrm{C}$.

A massa fresca total das sementes foi determinada em balança analítica. Após pesagem, retiraram-se os integumentos das sementes, obtendo-se quatro cotilédones. Destes, dois (um de cada semente) foram pesados e mergulhados em nitrogênio líquido, para posterior determinação dos teores protéicos. Para obtenção da massa seca, os outros dois cotilédones e os integumentos foram pesados e transferidos para estufa com ventilação forçada, por aproximadamente 48 horas, a $75^{\circ} \mathrm{C}$, até atingir massa constante.

Para extração das proteínas, os cotilédones foram homogeneizados em almofariz e pistilo, com $10 \mathrm{~mL}$ de $\mathrm{NaOH}$ $0,1 \mathrm{~mol} . \mathrm{L}^{-1}$. O extrato, assim obtido, foi centrifugado a $2.500 \mathrm{~g}$, por um período de cinco minutos. Em seguida, uma alíqüota de $100 \mu \mathrm{L}$ foi tomada para a determinação de proteínas pelo método "dye-binding" de Bradford (1976), utilizando soroalbumina bovina (BSA) como padrão.

Em todos os experimentos, as unidades experimentais foram constituídas por um frasco contendo um explante. Os tratamentos, repetidos seis vezes, foram dispostos inteiramente ao acaso e os seus efeitos foram analisados pelo teste de Tukey a 5\% de probabilidade.

\section{Resultados e Discussão}

O ácido naftaleno-acético (ANA) e o ácido giberélico $\left(\mathrm{GA}_{3}\right)$ não afetaram a massa seca das sementes, que foi estimulada pela benziladenina (BA) e inibida pelo ácido abscísico (ABA) apenas nas concentrações mais elevadas (tabela 1). Isso indica que as sementes de soja, no estádio utilizado, podem conter auxinas e giberelinas em quantidade suficiente para seu crescimento e que citocininas podem estimular o transporte de assimilados às sementes, além de causar expansão celular, o que estaria associada ao aumento 
Tabela 1. Efeito de diferentes concentrações do ácido naftaleno-acético (ANA), ácido giberélico (GA), benziladenina (BA) e ácido abscísico (ABA) sobre o acúmulo de massa seca em sementes de soja cultivadas in vitro durante 10 dias. D0 = controle in situ dia 0; D10 = controle in situ dia 10; SF = explante sem fitorregulador. Médias seguidas de pelo menos uma mesma letra não diferem entre si pelo teste de Tukey $(\mathrm{p} \leq 0,05)$.

Table 1. Effect of different concentrations of naphthalene acetic acid (NAA), gibberellic acid (GA $)$, benzyladenine (BA) and abscisic acid (ABA) on the increans of dry mass of in soybean seeds cultived in vitro during 10 days. D0 = control in situ day 0; D10 = control in situ day 10; SF = explant without growth regulator. Averages followed by at least one same letter are not significantly different in Tukey test $(\mathrm{p} \leq 0,05)$.

\begin{tabular}{|c|c|c|c|c|c|c|c|}
\hline \multirow[t]{2}{*}{ Fitorreguladores } & \multicolumn{7}{|c|}{ Massa seca (mg) } \\
\hline & D0 & D10 & $\mathrm{SF}$ & $10^{-7} \mathrm{M}$ & $10^{-6} \mathrm{M}$ & $10^{-5} \mathrm{M}$ & $10^{-4} \mathrm{M}$ \\
\hline ANA & 37,3 & 153,7 & $146,0 \mathrm{a}$ & $147,3 \mathrm{a}$ & $147,7 \mathrm{a}$ & $148,0 \mathrm{a}$ & $146,3 \mathrm{a}$ \\
\hline $\mathrm{GA}_{3}$ & 35,3 & 159,3 & $141,0 \mathrm{a}$ & $140,0 \mathrm{a}$ & $137,7 \mathrm{a}$ & $137,3 \mathrm{a}$ & $134,7 \mathrm{a}$ \\
\hline $\mathrm{BA}^{3}$ & 36,4 & 166,2 & $152,4 \mathrm{~b}$ & $153,2 b$ & $157,2 \mathrm{ab}$ & $159,6 \mathrm{a}$ & $162,0 \mathrm{a}$ \\
\hline $\mathrm{ABA}$ & 35,3 & 161,0 & $141,3 \mathrm{a}$ & $134,3 \mathrm{ab}$ & $133,7 \mathrm{ab}$ & $130,0 \mathrm{~b}$ & $126,0 \mathrm{~b}$ \\
\hline
\end{tabular}

na extensibilidade da parede celular (Taiz \& Zeiger 2002). Cho et al. (2002) avaliaram o efeito da aplicação de benzilaminopurina (BAP) sobre o crescimento de sementes de soja e observaram que $1 \mathrm{mmol}^{-1}$ de BAP aumentou a massa seca das sementes. Resultados semelhantes aos obtidos com soja são encontrados na literatura para outra leguminosa, a ervilha. Barrat (1986) e Sponsel (1982) avaliaram as relações existentes entre o crescimento de sementes de ervilha, medido com base no acúmulo de massa seca, e a quantidade de ANA presente nesses órgãos. Verificaram que a auxina, isoladamente, não alterou a quantidade de massa seca acumulada pelas sementes.

A giberelina, por sua vez, parece estar mais envolvida com o crescimento do pericarpo de vagens, pois, segundo observado por Barrat (1986), o $\mathrm{GA}_{3}$ estimulou o acúmulo de massa seca de pericarpo de frutos de ervilha, aumentando a força desse dreno ou mantendo-o como um dreno preferencial em detrimento das sementes.

O efeito estimulatório da BA sobre a massa seca das sementes ocorreu sempre nas concentrações acima de $10^{-6}$ mol. $\mathrm{L}^{-1}$ (tabela 1 ). Possivelmente a citocinina atue estimulando a atividade de dreno das sementes, no entanto isso parece depender da quantidade de BA presente nos órgãos, como também foi observado por Barrat (1986) em ervilha. Esse autor verificou, em um sistema artificial de cultivo, que $10^{-4}$ mol.L $\mathrm{L}^{-1}$ de BA foi a concentração que proporcionou o maior crescimento das sementes.

Dentre os quatro fitorreguladores utilizados isoladamente, o ABA foi o único que causou inibição no crescimento das sementes (tabela 1). O efeito inibitório ocorreu nas concentrações de $10^{-5}$ e $10^{-4}$ mol.L-1 ${ }^{-1}$ Ao que parece, o $\mathrm{ABA}$, ao contrário da $\mathrm{BA}$, atuou inibindo a atividade de dreno das sementes, no estádio de desenvolvimento utilizado, conseqüentemente, o fluxo de nutrientes aos frutos diminuiu e o crescimento foi inibido. Essa idéia pode ser reforçada pelos resultados de Eeuwens \& Schwabe (1975), também com ervilha. Analisando o crescimento desses frutos submetidos a diferentes concentrações de ABA, os autores verificaram uma correlação entre o declínio na taxa de crescimento das sementes e o aumento acentuado nos teores de ABA nesses tecidos. Resultados semelhantes foram obtidos por Schussler et al. (1984), os quais observaram que o ABA causou diminuição no crescimento de sementes de soja in vitro e que os níveis de ABA nas sementes tenderam a decrescer durante o desenvolvimento, na medida em que essas estruturas acumulavam massa seca. Devido aos resultados obtidos com o ABA, optou-se por não utilizá-lo em combinação com os outros fitorreguladores.

Após avaliação do efeito isolado dos fitorreguladores sobre o crescimento das sementes, foi feita a combinação dos mesmos, exceto o ABA, dois a dois, fixando a concentração de um deles e variando a do outro. Apenas a combinação entre ANA e BA proporcionou aumento na massa seca das sementes (tabela 3), ao contrário do que ocorreu com a combinação entre $\mathrm{GA}_{3}$ e ANA, que inibiu o crescimento das sementes (tabela 3). Todas as outras combinações, ou sejam, ANA com GA, GA GA $_{3}$ com BA, BA com ANA e BA com $\mathrm{GA}_{3}$ (dados não mostrados) não influenciaram o teor de massa seca das sementes de soja no estádio de desenvolvimento utilizado no 
experimento. Ao que parece, os hormônios vegetais atuam sobre o crescimento das sementes, entretanto seus efeitos dependem, além das quantidades presentes nos tecidos, de interações que podem ocorrer entre eles.

Verificou-se que ANA, nas concentrações de $10^{-7}$, $10^{-6}$ e $10^{-5}$ mol.L $L^{-1}$, não alterou os teores protéicos das sementes. Entretanto, quando essas foram cultivadas em $10^{-4}$ mol. $L^{-1}$ de ANA, observou-se aumento no teor protéico, proporcionando produções significativamente superiores àquelas do tratamento controle (tabela 2). Isso permite sugerir que auxinas podem estimular a síntese de proteínas em sementes de soja, no entanto, este processo parece depender da quantidade endógena desse fitohormônio. Veluthambi \& Poovaiah (1984) observaram o mesmo efeito do ANA em frutos de morango. De acordo com Van Huizen et al. (1996), o ácido cloroindol-3-acético, auxina endógena em frutos de ervilha, induz a síntese de proteínas, o que está de acordo com os presentes resultados com frutos de soja.

Os resultados apresentados na tabela 2 mostram que o $\mathrm{GA}_{3}$, aplicado exogenamente e nas doses utilizadas, não alterou a produção de proteínas nas sementes. Isso pode ter ocorrido em função dos níveis endógenos de giberelinas que, possivelmente, são elevados nas sementes de soja em desenvolvimento. Segundo Ozga et al. (1992) e Van Huizen et al. (1996), giberelinas são constituintes naturais de sementes de ervilha em desenvolvimento, as quais apresentam altos níveis do fitormônio. O metabolismo das giberelinas é regulado endogenamente de forma a manter o nível de giberelinas ativas praticamente constante. Quando giberelinas são fornecidas às plantas, uma proporção torna-se glicosilada, conseqüentemente inativa (Schneider \&
Schmidt 1990). Isso pode, pelo menos em parte, explicar os resultados obtidos no experimento, que foram semelhantes aos obtidos por Groot et al. (1987) em sementes de tomate.

A benziladenina proporcionou incremento no teor protéico dos cotilédones, nas quatro concentrações utilizadas (tabela 2), indicando que citocinina é, possivelmente, um fitohormônio que influencia a produção de proteínas em frutos de soja. Segundo D’Agostino et al. (2000), aumento na expressão de genes é um dos efeitos primários das citocininas. De modo oposto, o ABA foi o único, de todos os fitorreguladores utilizados isoladamente, a causar decréscimo acentuado nos teores de proteínas dos cotilédones de soja (tabela 2), levando a supor que, ao contrário do que ocorre com auxinas e citocininas, o ABA inibe a produção de proteínas de reserva em frutos imaturos de soja.

As adições simultâneas de ANA a $10^{-5}$ mol. $\mathrm{L}^{-1} \mathrm{e}$ de $\mathrm{GA}_{3}$ a $10^{-7}, 10^{-6}$ ou $10^{-5} \mathrm{~mol} . \mathrm{L}^{-1}$, promoveram aumento no teor protéico cotiledonar, relativamente àquele verificado com apenas ANA a $10^{-5}$ mol.L $\mathrm{L}^{-1}$. Porém, o aumento da concentração de $\mathrm{GA}_{3}$ para $10^{-4}$ mol. $\mathrm{L}^{-1}$ resultou em um teor de proteínas da mesma grandeza que o observado com ANA a $10^{-5}$ mol.L - $^{-1}$ (tabela 4). Ao que parece, concentrações elevadas de $\mathrm{GA}_{3}$, pelo menos a partir de $10^{-4}$ mol.L $\mathrm{L}^{-1}$, podem ter efeito inibitório sobre a produção de proteínas em sementes imaturas de soja, visto que com o aumento da concentração isolada de $\mathrm{GA}_{3}$ obteve-se decréscimo do teor de proteínas (tabela 2). O contrário ocorreu com a aplicação de ANA, ou seja, sob as maiores concentrações desta auxina, verificaram-se os maiores

Tabela 2. Efeito de diferentes concentrações do ácido naftaleno-acético (ANA), ácido giberélico (GA $)$, benziladenina (BA) e ácido abscísico (ABA) sobre o acúmulo de proteínas em sementes de soja cultivadas in vitro durante 10 dias. D0 = controle in situ dia 0; D10 = controle in situ dia 10; SF = explante sem fitorregulador. Médias seguidas de pelo menos uma mesma letra não diferem entre si pelo teste de Tukey $(\mathrm{p} \leq 0,05)$.

Table 2. Effect of different concentrations of naphthalene acetic acid (NAA), gibberellic acid (GA $)$, benzyladenine (BA) and abscisic acid (ABA) on the increase of dry mass of in soybean seeds cultived in vitro during 10 days. D0 = control in situ day $0 ; \mathrm{D} 10=$ control in situ day $10 ; \mathrm{SF}=$ explant without growth regulador. Averages followed by at least one same letter are not significantly different in Tukey test $(\mathrm{p} \leq 0,05)$.

\begin{tabular}{|c|c|c|c|c|c|c|c|}
\hline \multirow[t]{2}{*}{ Fitorreguladores } & \multicolumn{7}{|c|}{ Proteína $\left(\mu \mathrm{g} \cdot \mathrm{gMF}^{-1}\right)$} \\
\hline & D0 & D10 & SF & $10^{-7} \mathrm{M}$ & $10^{-6} \mathrm{M}$ & $10^{-5} \mathrm{M}$ & $10^{-4} \mathrm{M}$ \\
\hline ANA & 43,0 & 92,7 & $74,8 \mathrm{~b}$ & $74,8 \mathrm{~b}$ & $74,7 \mathrm{~b}$ & $76,7 \mathrm{~b}$ & $81,5 \mathrm{a}$ \\
\hline $\mathrm{GA}_{3}$ & 48,0 & 86,2 & $98,8 \mathrm{ab}$ & $99,2 \mathrm{a}$ & $100,3 \mathrm{a}$ & $100,8 \mathrm{a}$ & $95,2 \mathrm{~b}$ \\
\hline $\mathrm{BA}^{3}$ & 48,0 & 91,0 & $82,0 \mathrm{c}$ & $88,4 \mathrm{~b}$ & $92,2 \mathrm{a}$ & $92,0 \mathrm{a}$ & $91,0 \mathrm{ab}$ \\
\hline $\mathrm{ABA}$ & 43,0 & 91,8 & $92,8 \mathrm{a}$ & $87,8 \mathrm{~b}$ & $82,7 \mathrm{c}$ & $78,0 \mathrm{~d}$ & $77,8 \mathrm{~d}$ \\
\hline
\end{tabular}


Tabela 3. Efeito da combinação entre diferentes fitorreguladores sobre o acúmulo de massa seca em sementes de soja cultivadas in vitro durante 8 dias. D0 = controle in situ dia 0; D8 = controle in situ dia 8; SF = explante sem fitorregulador. Médias seguidas de pelo menos uma mesma letra não diferem entre si pelo teste de Tukey $(\mathrm{p} \leq 0,05)$. ${ }^{1} \mathrm{O}$ segundo fitorregulador apresenta diferentes concentrações.

Table 3. Effect of a combination of growth regulators on the increase of dry mass in soybean seeds cultived in vitro during 8 days. D0 = control in situ day 0; D8 = control in situ day 8; SF = explant without grow regulador. Averages followed by at least one same letter are not significantly different in Tukey test $(\mathrm{p} \leq 0,05)$. ${ }^{1}$ The second phytoregulator presents different concentrations.

\begin{tabular}{lccccccc}
\hline Fitorreguladores $^{1}$ & \multicolumn{7}{c}{ Massa seca $(\mathrm{mg})^{-10}$} \\
\cline { 2 - 7 } & D0 & D10 & SF & $10^{-7} \mathrm{M}$ & $10^{-6} \mathrm{M}$ & $10^{-5} \mathrm{M}$ & $10^{-4} \mathrm{M}$ \\
\hline ANA $10^{-5} \mathrm{M}+\mathrm{BA}$ & 41,3 & 156,0 & $135,7 \mathrm{c}$ & $140,0 \mathrm{bc}$ & $144,0 \mathrm{ab}$ & $144,7 \mathrm{ab}$ & $147,7 \mathrm{a}$ \\
GA $_{3} 10^{-7} \mathrm{M}+\mathrm{ANA}$ & 42,0 & 145,0 & $132,0 \mathrm{a}$ & $128,0 \mathrm{ab}$ & $122,3 \mathrm{bc}$ & $120,0 \mathrm{c}$ & $118,0 \mathrm{c}$ \\
\hline
\end{tabular}

teores de proteínas (tabela 2). Resultados semelhantes ocorreram com a combinação do ANA, sob a mesma concentração, com a BA, nas concentrações de $10^{-7}$, $10^{-6}, 10^{-5}$ e $10^{-4}$ mol.L ${ }^{-1}$ (tabela 4 ), sugerindo que a citocinina, isoladamente, induz a síntese de proteínas de reserva em sementes de soja (tabela 2). Quando combinada com ANA (tabela 4), BA promoveu aumento no nível protéico apenas sob $10^{-7}, 10^{-6}$ e $10^{-5}$ mol.L ${ }^{-1} \mathrm{e}$ diminuiu sob $10^{-4}$ mol. $\mathrm{L}^{-1}$. Isso indica que, quando combinados, os hormônios vegetais influenciam diferentemente o acúmulo de proteínas em sementes de soja, pois pode ocorrer interações entre eles que determinam efeitos aditivos ou antagônicos, dependendo de suas concentrações.

A benziladenina a $10^{-4}$ mol. $\mathrm{L}^{-1}$, combinada com o $\mathrm{GA}_{3}$ em diferentes concentrações (tabela 4), levou à queda no acúmulo de proteínas em cotilédones de soja nas concentrações mais elevadas de $\mathrm{GA}_{3}$, ou sejam, $10^{-5}$ e $10^{-4}$ mol.L ${ }^{-1}$. Comparando os teores de proteínas na ausência de BA $\left(82 \mu \mathrm{g} . \mathrm{gMF}^{-1}\right)$ com BA a $10^{-4}$ mol.L $\mathrm{L}^{-1}$ (91 $\mu \mathrm{g} . \mathrm{gMF}^{-1}$ ), observa-se um incremento, estatisticamente diferente, de $11 \%$ (tabela 2). Uma vez que não se obteve diferença entre as várias concentrações de giberelina, supõe-se que o aumento na concentração desta tenha sido responsável pelo decréscimo no teor de proteínas quando combinada com BA (tabela 4).

$\mathrm{O} \mathrm{GA}_{3}$ em concentrações mais elevadas $\left(10^{-5} \mathrm{e}\right.$ $10^{-4}$ mol. $\left.\mathrm{L}^{-1}\right)$ reverteu o efeito positivo causado pela BA, tendo em vista que houve queda de $20 \%$ no teor protéico das sementes, comparando o controle sem fitoregulador (T0) com a combinação de BA $10^{-4} \operatorname{com} \mathrm{GA}_{3}$

Tabela 4. Efeito da combinação entre diferentes fitorreguladores sobre o acúmulo de proteínas em sementes de soja cultivadas in vitro durante 8 dias. D0 = controle in situ dia $0 ; \mathrm{D} 8=$ controle in situ dia $8 ; \mathrm{SF}=$ explante sem fitorregulador. Médias seguidas de pelo menos uma mesma letra não diferem entre si pelo teste de Tukey $(\mathrm{p} \leq 0,05)$. ${ }^{1} \mathrm{O}$ segundo fitorregulador apresenta diferentes concentrações.

Table 4. Effect of a combination of growth regulators on the increase of dry mass accumulate protein in soybean seeds cultived in vitro during 8 days. D0 (control in situ day 0), D8 (control in situ day 8), SF (explant without growth regulators. Averages followed by at least one same letter is not significantly different in Tukey test $(p \leq 0,05)$. ${ }^{1}$ The second phytoregulator presents different concentrations.

\begin{tabular}{|c|c|c|c|c|c|c|c|}
\hline \multirow[t]{2}{*}{ Fitorreguladores $^{1}$} & \multicolumn{7}{|c|}{ Proteína $\left(\mu \mathrm{g} . \mathrm{gMF}^{-1}\right)$} \\
\hline & D0 & D10 & $\mathrm{SF}$ & $10^{-7} \mathrm{M}$ & $10^{-6} \mathrm{M}$ & $10^{-5} \mathrm{M}$ & $10^{-4} \mathrm{M}$ \\
\hline ANA $10^{-5} \mathrm{M}+\mathrm{GA}_{3}$ & 51,0 & 84,0 & $87,0 \mathrm{~b}$ & $92,0 \mathrm{a}$ & $93,0 \mathrm{a}$ & $94,0 \mathrm{a}$ & $88,0 \mathrm{~b}$ \\
\hline ANA $10^{-5} \mathrm{M}+\mathrm{BA}^{3}$ & 51,0 & 84,0 & $82,0 \mathrm{~b}$ & $89,7 \mathrm{a}$ & $88,3 \mathrm{a}$ & $87,8 \mathrm{a}$ & $80,0 \mathrm{~b}$ \\
\hline $\mathrm{BA} 10^{-4} \mathrm{M}+\mathrm{GA}_{3}$ & 50,0 & 64,0 & $69,0 \mathrm{a}$ & $68,0 \mathrm{a}$ & $68,3 \mathrm{a}$ & $62,0 \mathrm{~b}$ & $55,2 \mathrm{c}$ \\
\hline BA $10^{-4} \mathrm{M}+$ ANA & 50,7 & 74,0 & $72,0 \mathrm{~b}$ & $78,0 \mathrm{a}$ & $79,0 \mathrm{a}$ & $78,8 \mathrm{a}$ & $80,0 \mathrm{a}$ \\
\hline $\mathrm{GA}_{3} 10^{-7} \mathrm{M}+\mathrm{ANA}$ & 51,0 & 74,0 & $98,0 \mathrm{a}$ & $96,0 \mathrm{ab}$ & $92,8 \mathrm{c}$ & $93,0 \mathrm{bc}$ & $87,2 \mathrm{~d}$ \\
\hline $\mathrm{GA}_{3} 10^{-7} \mathrm{M}+\mathrm{BA}$ & 49,1 & 69,5 & $66,8 \mathrm{a}$ & $66,0 \mathrm{a}$ & $65,0 \mathrm{ab}$ & $61,0 \mathrm{bc}$ & $60,0 \mathrm{c}$ \\
\hline
\end{tabular}


$10^{-4}$ mol.L. $\mathrm{L}^{-1}$ (T4) (tabela 4). Os resultados indicam que, possivelmente, ocorreu uma interação negativa entre GA e BA a qual foi responsável pelo efeito inibitório sobre a produção de proteínas. Isso é reforçado pelos resultados de Cao \& Shannon (1997). Estes autores mostraram que o efeito do $\mathrm{GA}_{3}$ sobre a produção de proteínas em sementes jovens de milho depende da concentração utilizada; em baixas concentrações de $\mathrm{GA}_{3}$ ( 5 e $30 \mu \mathrm{mol} . \mathrm{L}^{-1}$ ) houve aumento no teor de proteínas nas sementes, enquanto que a $50 \mu \mathrm{mol} . \mathrm{L}^{-1}$ não houve efeito sobre a síntese protéica. Segundo os autores, $50 \mu$ mol.L $L^{-1}$ de $\mathrm{GA}_{3}$ pode ter sido uma concentração muito elevada, levando aos resultados obtidos. Isso pode também ter ocorrido no presente experimento, uma vez que com o aumento do $\mathrm{GA}_{3}$ houve decréscimo no teor de proteínas das sementes.

Na tabela 4 observam-se os resultados das adições simultâneas de BA a $10^{-4}$ mol. $\mathrm{L}^{-1}$ e ANA em diversas concentrações $\left(10^{-7}, 10^{-6}, 10^{-5}\right.$ e $10^{-4}$ mol. $\left.\mathrm{L}^{-1}\right)$. Verificou-se que as diversas concentrações de ANA diferiram do controle sem BA, porém não entre si, indicando que o aumento de ANA, quando combinado com BA a $10^{-4}$ mol.L $L^{-1}$, não influenciou no acúmulo de proteínas em sementes imaturas de soja.

A tabela 4 mostra os resultados promovidos pelas combinações entre $\mathrm{GA}_{3}$ e ANA e entre $\mathrm{GA}_{3}$ e BA. Nessas combinações, a concentração da giberelina foi fixada em $10^{-7}$ mol. $\mathrm{L}^{-1}$ e as concentrações de ANA e BA variaram $\left(10^{-7}, 10^{-6}, 10^{-5}\right.$ e $10^{-4}$ mol.L $\left.L^{-1}\right)$. Verificou-se que o resultado de ambas as misturas foi semelhante, ocorrendo uma tendência de decréscimo no teor de proteínas nos cotilédones à medida em que se aumentaram as concentrações da auxina (tabela 4) e da citocinina (tabela 4). Resultados semelhantes foram obtidos quando se combinou os mesmos fitorreguladores, porém com $\mathrm{GA}_{3}$ em diferentes concentrações $\left(10^{-7}, 10^{-6}\right.$, $10^{-5}$ e $10^{-4}$ mol. $L^{-1}$ ) e auxina (tabela 4 ) e citocinina (tabela 4) em uma única concentração. Verificou-se, portanto, que houve efeito antagônico nas combinações e nas concentrações utilizadas. Isso demonstra que, quando combinados, os fitorreguladores atuam de maneira diferente da observada quando são utilizados isoladamente, podendo ocorrer efeito de interação, positiva ou negativa, dependendo da combinação e concentrações utilizadas.

Portanto, em sementes de soja, no estádio de desenvolvimento utilizado no presente trabalho, o teor de proteínas foi afetado tanto pelo tipo de fitorregulador como pela concentração e combinações utilizadas, como verificado por Van Huizen et al. (1996), em frutos de ervilha. Assim, embora freqüentemente se discuta a ação isolada dos hormônios vegetais, deve-se sempre atentar para as possíveis inter-relações entre os mesmos. $\mathrm{O}$ mecanismo de ação dos hormônios vegetais, em nível de alteração na síntese protéica via expressão genética, depende da interação entre estes e de suas concentrações no tecido, o que é influenciado pelos níveis endógenos e exógenos.

\section{Referências bibliográficas}

BARRAT, D.H.P. 1986. In vitro pod culture of Pisum sativum. Plant Science 43:223-228.

BRADFORD, M.M. 1976. A rapid and sensitive method for the quantitation of microgram quantities of protein utilizing the principle of protein-dye binding. Analytical Biochemistry 72:248-254.

CAO, H. \& SHANNON, J.C. 1997. Effect of gibberellin on growth, protein secretion and starch accumulation in maize endosperm suspension cells. Journal of Plant Growth Regulation 16:37-140.

CHO, Y., SUH, S.K., PARK, H.K. \& WOOD, A. 2002. Impact of 2,4-DP and BAP upon pod set and seed yield in soybean treated at reproductive stages. Plant Growth Regulation 36:215-221.

D’Agostino, B., DERUERE, J. \& KIEBER, J.J. 2000. Characterization of the response of the Arabdopsis ARR gene family to cytokinin. Plant Physiology 124:1706-1771.

EEUWENS, C.J. \& SCHWABE, W.W. 1975. Seed and pod wall development in Pisum sativum L. in relation to extracted and applied hormones. Journal of Experimental Botany 26:1-14.

GROOT, S.P.C., JOHAN, B. \& KARSSEN, C.M. 1987. The role of endogenous gibberellin in seed and fruit development of tomato: studies with a gibberellin-deficient mutant. Physiologia Plantarum 71:184-190.

HOAGLAND, D.R. \& ARNON, D.I. 1938. The water-culture method for growing plants without soil. Circular 347. Agricultural Experiment Station, University of California, p.1-39.

JUNGHANS, T.G. \& MOSQUIM, P.R. 1995. Atividade da sintetase da glutamina e sintase do glutamato em explantes de frutos de soja sob diferentes fontes de nitrogênio. Revista Brasileira de Fisiologia Vegetal 7:67-74.

MOSQUIM, P.R. \& SODEK, L. 1991. Culture of soybean fruit explants: growth conditions and efficiency of nitrogen sources for reserve protein synthesis. Plant Cell, Tissue and Organ Culture 27:71-76.

NASCIMENTO, R., MOSQUIM, P.R., ARAÚJO, E.F. \& SANTANNA, R. 1998. Distribuição de amido, açúcares solúveis e atividades de invertases em explantes de soja sob várias concentrações de sacarose e diferentes fontes de nitrogênio. Revista Brasileira de Fisiologia Vegetal 10:125-130. 
OBENDORF, R.L., RYTKO, G.T. \& BYRNE, M.C. 1983. Soybean seed growth and maturation by in vitro pod culture. Annals of Botany 51:217-227.

OZGA, J.A., BRENNER, M.L. \& REINECKE, D.M. 1992. Seed effects on giberellin metabolism in pea pericarp. Plant Physiology 100:88-94.

SCHNEIDER, G. \& SCHMIDT, J. 1990. Conjugation of gibberellins in Zea mays L. In Plant growth substances (R.P. Pharis \& S.B. Rood, eds.). Springer, Heidelberg, p.300-306.

SCHRADER, L.E. \& THOMAS, R.J. 1981. Nitrate uptake, reduction and transport in the whole plant. In Nitrogen and carbon metabolism (J.D. Bewley, ed.). Martins Nijhoff / Dr W. Junk Publishers, The Hague, p.49-93.

SCHUSSLER, J.R., BRENNER, M.L. \& BRUN, W.A. 1984. Abscisic acid and its relationship to seed filling in soybeans. Plant Physiology 76:301-306.

SPONSEL, V.M. 1982. Effects of applied gibberellins and naphthylacetic acid on pod development in fruits of Pisum sativum L. cv. Progress n. 9. Journal of Plant Growth Regulation 1:147-152.
TAIZ, L. \& ZEIGER, L. 2002. Plant Physiology. $3^{\text {rd }}$ ed. Sinauer Associates, Sunderland.

THOMPSON, J.F., MADISON, J.T. \& MUENSTER, A.M.E. 1977. In vitro culture of immature cotyledons of soybean (Glycine max [L.] Merril). Annalytical Botany 41:29-39.

THORNE, J.H. 1981. Morphology and ultrastructure of maternal seedcoat tissues of soybean in relation to the import of photosynthate. Plant Physiology 67:1016-1025.

THORNE, J.H. \& RAINBIRD, R.M. 1983. An in vivo technique for the study of phloem unloading in seed coats of developing soybean seeds. Plant Physiology 72:268-271.

VAN HUIZEN, R., OZGA, J.A. \& REINECKE, D.M. 1996. Influence of auxin and gibberellin on in vivo protein synthesis during early pea fruit growth. Plant Physiology 112:53-59.

VAN HUIZEN, R., OZGA, J.A. \& REINECKE, D.M. 1997. Seed and hormonal regulation of gibberellins 20-oxidase expression in pea pericarp. Plant Physiology 115:123-128.

VELUTHAMBI, K. \& POOVAIAH, B.W. 1984. Auxin regulated polypeptide changes at different stages of strawberry fruit development. Plant Physiology 75:349-353. 